\title{
Senaste nytt i institutionens skriftserier våren 2005
}

För frågor om Växjö University Press, abonnemang på Acta Wexionensia, eller köp av enskilda volymer, kontakta:

Kerstin Brodén, redaktör på Växjö University Press

E-post: Kerstin.Broden@adm.vxu.se

Telefon: 0470-708267.

Acta Wexionensia. Nr 502004.

Gamla plikter och nya krav. En studie om egendom, kvinnosyn och äldreomsorg i det svenska agrarsamhället 1815-1939.

Ulla Rosén. ISBN: 91-7636-429-1. Pris: 160

$\mathrm{kr}+$ moms.

Syftet med denna studie har varit att analysera de förändringar som inträffade för de äldre när den traditionellt familjebaserade omsorgen gradvis kom att ersättas med en offentligt organiserad. Studien tar fasta på det patriarkala samhällets omvandling till ett välfärdssamhälle utifrån ett genusperspektiv. De fortlevande patriarkala inslagen i samhället har kraftigt begränsat och motverkat kvinnors självständighet. De har satts i relation till - fadern, brodern, maken utifrån ett normsystem som i mycket stor utsträckning har påverkat uppbyggnaden av det svenska välfärdssamhället.

Ulla Rosén belyser denna process utifrån äldreomsorgens omvandling.

I två områden, Herrestads härad och Kumla socken, har olikheter i egendomsfördelning och social struktur påvisats och kopplats samman med både fattigvårdens organisering och de äldres egna strategier för omsorg. Fram till 1910 blev verksamheten mer institutionaliserad, men den grundades fortfarande på liknande värderingar som i början av 1800-talet. Under denna period fungerade egendom som en "pensionsförsäkring". De som saknade resurser förlitade sig på egna åtgärder i form av arbete eller sparande och utnyttjande sina egna sociala nätverk. Ett kontinuitetsbrott konstateras framförallt i Kumla under 1930talet. Gränsen mellan det privata och det offentliga har förskjutits och kommunen och staten tar ett större ansvar för medborgaren.
Acta Wexionensia. Nr 562005.

Hechaluz - en rörelse i tid och rum. Tyskjudiska ungdomars exil i Sverige 1933-

1943. (doktorsavhandling i historia)

Malin Thor. ISBN: 91-7636-438-0. Pris:

$160 \mathrm{kr}+$ moms.

I slutet av 1800-talet och början av 1900-talet växte sionismen och den sionistiska rörelsen fram. Hechaluz och den pionjära ungdomsrörelsen utvecklades inom och delvis i opposition till den sionistiska rörelsen i Europa, men identifierade sig främst med Histadrut och den judiska arbetarrörelsen i Palestina. Hechaluz bestod av unga män och kvinnor som gick samman för att utbilda sig inom främst lantbruk med syftet att förbereda sig själva inför ankomsten till och uppbyggnaden av det judiska hemlandet, Eretz Israel.

Våren 1933 reste den svenske sionisten och veterinären Emil Glück, med anledning av nazisternas makttillträde, till Landesverband Hechaluz Deutschlands huvudkontor i Berlin för att erbjuda sig att ordna hachschara (utbildning) för dess medlemmar i Sverige. Emil Glück hade lyckats med att få Socialstyrelsen att etablera vad som skulle komma att kallas chaluz-kvoten. Kvoten innebar att tysk-judiska ungdomar fick tillstånd att resa in i Sverige som transmigranter för att utbildas inom lantarbete under 18 månader för att sedan fortsätta till Palestina.

Hechaluz - en rörelse i tid och rum är den första systematiska studien av chaluz-kvoten och Hechaluz verksamhet i Sverige 19331943. I boken diskuteras bland annat hur, varför och av vilka Hechaluz i Sverige etablerades, organiserades och utvecklades under åren 1933-1943 samt hur Hechaluz 
Äldreomsorg bedrivs inte längre som en familjär plikt i den privata sfären utan är del av de rättigheter de äldre kan kräva av samhället. Ett åldrande i trygghet övergår sakteliga till att bli en medborgerlig rättighet.

Acta Wexionensia. Nr 572005.

Face in cyberspace. Facework, (im)politeness and conflict in English discussion groups. (doktorsavhandling $i$ engelska)

Ibolya Maricic. ISBN: 91-7636-444-5. Pris: $160 \mathrm{kr}+$ moms.

Text-based group discussions on anything from news, politics, hobbies, sports, and pets now abound on the Internet and engage millions of people all over the world. Such group discussions pose specific challenges for the participants, particularly in situations of interpersonal conflict. Conflicts can potentially endanger the 'face' or public image and social identity of the participants even in allegedly 'faceless' textual interaction via the Internet. But why do interpersonal conflicts arise and proliferate in this medium? How do they evolve and how are they ended? How do large heterogeneous groups of people manage to handle their own and other people's 'faces' when they have only the written word at their disposal? These are some of the issues addressed in this study of the discourse and interaction practices of English discussion groups online. Its findings indicate that conflicts are easily triggered and escalated online and require substantial effort and verbal skill to counterbalance and terminate. togs emot i det svenska samhället. Med utgångspunkt i såväl samtida skriftliga källor som nutida insamlade levnadsberättelser undersöks även Hechaluz och dess medlemmars självbild, handlingsutrymme och syn på den egna verksamheten och exiltillvaron i Sverige.

Acta Wexionensia. Nr 582005.

Forskning om undervisning i främmande språk. Rapport från workshop i Växjö 1011 juni 2004.

Eva Larsson Ringqvist och Ingela

Valfridsson (red.). ISBN: 91-7636-450-X.

Pris: $160 \mathrm{kr}+$ moms.

Forskning om undervisning i främmande språk var temat för en nationell workshop som hölls vid Växjö universitet i juni 2004. Workshopen var ett led i ett nätverksbygge och denna volym, som dels innehåller en översiktsartikel över de olika föredrag som hölls vid workshopen, dels i en rad separata artiklar närmare behandlar flera av de presenterade forskningsprojekten, ger en god bild av språkdidaktisk forskning i Sverige idag. Workshopen blev ett tydligt bevis på att den språkdidaktiska forskningen är ett snabbt växande forskningsområde som inrymmer en mångfald av infallsvinklar och involverar forskare med många olika utgångspunkter. Bland de områden som berörs i artiklarna i denna samlingsvolym kan nämnas:

- kulturmöten/kulturskillnader/bilden av det främmande

- skönlitteraturens roll i språkundervisningen

- inlärarstilar och inlärarstrategier

- gruppens roll i inlärningen

- ordinlärning

- utvecklingsstadier och inlärningsgångar

- medvetandegörande och explicit kunskap

- lärarprinciper och lärares föreställningar

- mål och praktik i språkundervisningen

- utvärdering av språkundervisning

\section{Svenskans beskrivning 27. Förhandlingar vid Tjugosjunde sammankomsten för} svenskans beskrivning. Växjö den 14 och 15 maj 2004.

Gunilla Byrman, Jan Einarsson, Solveig Hammarbäck, Maria Lindgren, Per Stille (utg.). Växjö University Press. ISBN: 91-7636-457-7. Pris: $160 \mathrm{kr}+$ moms.

Vid olika universitet i Sverige och Finland har sedan 1963 regelbundet anordnats 
sammankomster för svenskans beskrivning. Vid dessa har forskningsresultat som rör svenska språkets uppbyggnad och användning presenterats och diskuterats.

Tjugosjunde sammankomsten för svenskans beskrivning ägde rum den 14 och 15 maj 2004 i Växjö. Temat för plenarföreläsningarna var Svenska - lokalt och globalt. De övriga presentationerna hörde hemma inom en rad olika områden, bl.a. tvåspråkighetsforskning, fonetik, grammatik, samtalsforskning samt text- och diskursanalys.

I denna volym publiceras i bearbetad form 37 av de föredrag som hölls vid sammankomsten. Den ger därmed en god överblick över aktuell forskning om svenska språket. Alla som vill följa den senaste utvecklingen på området finner här mycket av intresse. 